\title{
Uterine Contraction Frequency
}

National Cancer Institute

\section{Source}

National Cancer Institute. Uterine Contraction Frequency. NCI Thesaurus. Code C92905.

The number of uterine contractions recorded over a period of time, usually in minutes;

measured from the start of one contraction to the start of the next. 